\title{
Optimising the Number of Pumps and Balancing Valves in Chilled Water Distribution Systems
}

\author{
Adrian Retezan ${ }^{1,}$, Szilveszter Geyer Ehrenberg ${ }^{1, *}$ \\ ${ }^{1}$ Universitatea Politehnica Timisoara, Romania
}

\begin{abstract}
Everyday life does involve use of cooling systems for different areas and scenarios. We use them to keep our thermal comfort level at optimum, either to get rid of some extra heat from technological systems. From various cooling solutions, one and very common system is the chilled water system, where centralised chiller plants produce the cooling energy and all terminal units do receive cooling energy using a distribution loop. According to statistical data, electrical energy consumption of pumps might be up to $17 \%$ of entire electrical use of the cooling plant. When designing our cooling system loads during operation will not be same all the time. Variation must be treated accordingly, therefore to get best efficiency of the system, we must get a good control. Beside shut-off motorised valves our balancing must be considered in different scenarios. The paper looks to summarize the challenges in getting a good balancing and energy efficiency in chilled water distribution system.
\end{abstract}

\section{General Challenges of Distribution Loop}

Everyday life does involve use of cooling systems for different areas and scenarios. We use them to keep our thermal comfort level at optimum, either to get rid of some extra heat from technological systems. From various cooling solutions, one and very common system is the chilled water system, where centralised chiller plants produce the cooling energy and all terminal units do receive cooling energy using a distribution loop. The presented solutions are used in commercial buildings as like offices, commercial centres, public institutions with large cooling demand and various gains in different spaces.

When we design our cooling system with proper hydraulic distribution we define some base information. One, and very important is the overall flow which is determined by relation of cooling capacity and $\Delta \mathrm{t}$ (temperature difference).

$$
\begin{aligned}
& Q=m^{*} c^{*} \Delta t \\
& \mathrm{~m}=\mathrm{Q} /\left(\mathrm{c}^{*} \Delta \mathrm{t}\right)
\end{aligned}
$$

Looking on equation 1 and 2 we can see, that Cooling Capacity (Q) is defined by mass flow (m), specific heat of medium (c), and temperature difference of leaving and returning temperature. $(\Delta \mathrm{t})$. Up to now, there is nothing new, just some well-known basic facts. When we define the hydraulic layout will result in sum of pressure losses $(\Delta \mathrm{p})$. These pressure losses do include the following losses of a circuit:

- Pressure losses on straight pipes

- Pressure losses on bends and tees

- Pressure losses on strainers and valves, including control valves and balancing valves.

- Pressure losses on heat exchanger coils.

Considering all these items we could see that in case of pressure losses, pipe lengths will be defined by the optimum piping route, with corresponding section (depending how many branches we have in one single circuit and how big their capacity is). Tees and bends are also dependent of above distribution schematic.

What is often overlooked is, that the more and much variable (by means of cooling power) units are combined in one single circuit, the more of the balancing effort will be. Pipe section can slightly define the mass flow over some areas, but in many cases balancing valves will do the difference.

The more balancing valves are connected in series from source to the last consumers, the sum of these pressure drops will increase the power demand of the pump. It does mean, that specific energy consumption will be higher.

Considering equation nr.3 - related to the Pumping energy definition we can see, that higher the pressure

\footnotetext{
* Corresponding author: $\underline{\text { szgeyer@gmail.com }}$
} 
demand is at the same flow, the higher the energy demand will be.

$$
P_{2}=Q_{m} * \Delta H^{*} g * \rho / 3,6^{*} 10^{6 *} \eta_{\text {pump }}
$$

Where,

$\mathrm{P}_{2}$ - Power demand of the pump [kW];

$\mathrm{Q}_{\mathrm{m}}-$ Volume flow of the pump $[\mathrm{m} 3 / \mathrm{h}]$;

$\Delta \mathrm{H}$ - Pressure head [mWS];

$\mathrm{g}-$ acceleration of gravity $[\mathrm{m} / \mathrm{s} 2]$;

$\rho$-density of medium $[\mathrm{kg} / \mathrm{m} 3]$;

$\eta_{\text {pump }}$ - pump efficiency.

We can simply see that if $\Delta H^{\prime}>\Delta H^{\prime}$, the P2' > P2'. Of course, this relation stays as long as other values are not changing.

Another practical part of designing and defining the hydraulic layout is that sizing of the system is done on worst case scenario, which that means maximum load conditions.

Depending on the cooling system destination - comfort cooling or technological cooling, maybe mixt of these maximum load condition is not always required. Actually, the peak load requirement in case of comfort cooling system will be present about 3\% of the total time.

When we do plan our balancing of the system, the balancing is done either by static or dynamic balancing.

When system is balanced by static means, it is done in the design scenario (maximum flow condition). Therefore, in case of part load (reduced capacity, reduced flow) we could assist higher pressure drops over balancing valves as well as lower efficiency.

When we design the system, it might use control valves with simply ON-OFF control, which means that either the coil is passed by chilled water or not, or in case of larger systems (e.g. larger ducted fancoil units, airhandlers, etc) with modulated control valves. Modulated control valves means that during the working period, it might be positioned interim between fully open and fully closed position.

To have a proper control over the control valves, we do design with valve authority, that is around $\mathrm{N}=0.5$. Valve authority between $0.0-1.0$ is calculated. Authority is defined by using Formula 4.

$$
N=\Delta p_{\text {valve }} / \Delta p_{\text {total }}
$$

Where,

$\mathrm{N}$ - valve authority, values between $0.0-1.0$

$\Delta \mathrm{p}_{\text {valve }}$ - pressure drop across the valve

$\Delta \mathrm{p}_{\text {total }}$ - total pressure loss of the loop.

To be able to control the system, we must consider a valve authority of 0.5 , which will allow to make a control of flow for static balancing. This authority must be obtained at valve fully opened. If we consider this fact, we can see that the pressure drop of the valve is half of the total pressure losses of loop. In different conditions, the higher authority will lead to energy waste.

If we consider variable flow systems, we could see that in case of most control valves closed (low load conditions) the pressure loss of the loop will be very low, mainly because it is low flow condition. In this case, the valve with nominal valve authority of 0.5 in design flow will have to deal with the head of the pump, therefore, there will be an overflow condition. [1]. To be sure we have a stable control, we must check the minimum authority of the balancing valve in given condition. Formula 5 is showing this calculation method:

$$
\beta^{\prime}{ }_{\text {min }}=\Delta p_{\text {valve_fully_open }} / H_{\text {pump. }} \text {. }
$$

Where:

$\beta^{\prime}{ }_{\text {min }}-$ minimum authority of valve - should be over 0.25 $\Delta \mathrm{p}_{\text {valve_fully_open }}-$ Pressure loss of valve fully open $\mathrm{H}_{\text {pump }}$ - pump head.

In variable systems the pump control it seems to be essential. If the pump is controlled based on pressure and the pump is equipped with VFD, pump head might change proportional to the flow. This means, that in case of proportional control, the head will be lower in low flow conditions than in design flow conditions.

Considering EC regulation 641/2009, where proportional pressure control for pumps is defined as standard control curve with 0 flow conditions and pump head equal to nominal head $\mathrm{H} / 2$ (half of the maximum head), we could see that in low flow conditions a good value for minimum authority of the valve will be easier achieved.

In case of constant differential control of the pump we might need to calculate with the use of constant differential pressure valve across some branches without pump on sub-distribution loop.

In case of uncontrolled pump curve this could be higher, consequently massive overflow could be measured in coils, as well as noise will be significantly higher.

To avoid overflow and to match control, we could use two alternatives:

- install a differential pressure controller

- $\quad$ use multiple pumps serving zones.

Using pumps and balancing and controlling valves is essential, both are dealing with possible massive cost, therefore what is the best ratio between them is critical factor.

A possible solution to simplify the balancing of some zones might be the use of dynamic balancing valves where we set the desired flow and a control valve is modulated to keep it at nominal value. Different manufacturers offer solutions for pressure independent characterized control valves. These controls are based either on constant flow measurements or on pressure regulator system, that moves the regulator body by means of differential pressure on inlet and outlet of the valve body. [3] In case of these balancing valve method, 
the advantage is that regardless of flow condition over pump, there is no change on the loop.

By means of balancing/zoning valves we have to consider that all the pressure drops means loss of energy. In hydraulic systems medium does move by means of pressure difference, therefore the energy is the pressure. When we put valves to control a constant pressure loss, or to balance the system we lose some energy, which we introduced at the source.

When we consider pumps and we size them, we always do it on design flow condition. As flow is given in HVAC systems by relation of thermal energy and temperature difference, pressure losses are defined by sum of local pressure losses across pipes, heat exchangers and all sort of control and balancing valves.

When sizing the pump, the head is calculated for the most unfavourable trace, which will give the maximum pressure drop on design flow condition. On other appliances the pressure drop needs to be adjusted accordingly by means of the balancing valves described above. This means, that on design flow condition, the units closer to the pump will receive higher pressure on direct return piping solution, while far units will receive pressure close to design conditions. In this case closer units balancing effort will be bigger. Fig. 1 shows similar condition:

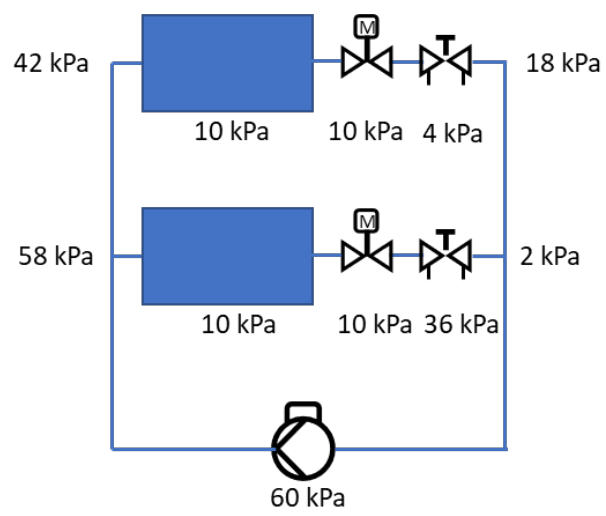

Fig.1 Balancing Valves setting example with 0.5 authority

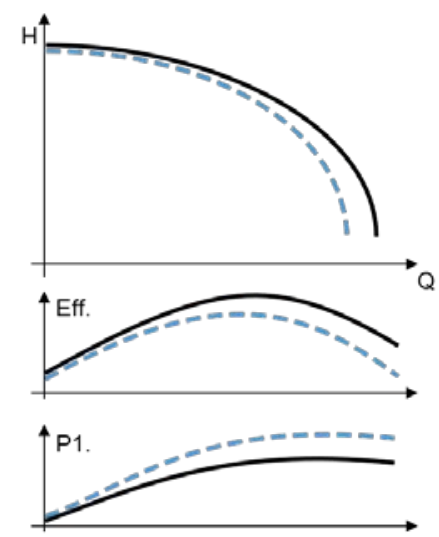

Fig.2 Pump curves - Q-H, Efficiency, Power curve
We can see, that in the above case the closer unit will have to deal with more pressure, effort will be higher.

While we are sizing the pump, this will be sized on design flow and on the maximum pressure needed.

Pumps should be selected close to its Best Efficiency Point (BEP), so it will use the less energy possible. When the pump is serving a variable flow system in part load conditions, the actual duty point will general result in lower efficiency. Fig.2 is showing a typical pump curve relation of Q-H, efficiency and power curve.

When Pump will supply lower flow and they are speed controlled by means of VFD and pressure transducers, they will consequently reduce their speeds to match the setpoint pressure. In this way it will create a new, reduced curve. In case of noncontrolled pumps, duty point in reduced flow conditions will be positioned along pump curve. This means in case of fixed speed centrifugal pumps lower flow and higher head.

Referring to Affinity Law, the head of the pump will change with the square of the speed change, while the power consumption will be cubic of the speed variation [4].

If we consider the variation of the HVAC system, most of the time we will meet part load conditions, which means lower flow rates than designed flow. In this way, in case of pump efficiency decrease we could say that the larger the number of unit is the more variation could appear and therefore the lower the global efficiency will be.

For this reason, we should analyse what is better to use: a) a pumping group - several pumps installed in cascade, b) zoning of the system, so we create different branches.

Considering scenario a), it means that we will install several pumps in parallel, so it will work in low conditions possible with higher or at least similar efficiency. In this case we still have to deal with the fact, that large distribution loops considered as one main loop will have installed several balancing valves in series, so total pressure drop summarised across balancing valves will be significant. A significantly high pressure loss over the valves will demand more power on pump.

Scenario b.), will make a split of the system, so we will deal with smaller loops, which will reduce the stress on the valves, we could use smaller pumps and also reliability will be much higher.

\section{Practical example of zoning}

\subsection{ON-OFF control valves}

Let's have an example where we consider a distribution loop built with one single pump and various balancing and controlling valves and the same loop with zoning. Our first example refers to ON-OFF control valves, where authority of the valve is not that critical. However, still overflows are subject that can't be avoided.

Fig. 3 is showing a main distribution with 2 different risers. In this case a single pump is used to feed all units. 
The closer riser to the pump is not only dealing with higher pressure, but also needs less water - This could be somehow balanced with using proper pipe sections, but since they are standard diameters, we could easily find situations where the diameter can't help limiting the water quantity. Here the balancing valves will have to take the effort. One that is the most probably needed is to use smaller diameter valves than the pipe diameter itself. With lower KV value larger pressure drop will be obtained over the balancing valve fully opened. In this case we can see that already a $27.5 \mathrm{kPa}$ pressure drop is needed on the first branch, while the second is $9 \mathrm{kPa}$, which is at nominal diameter.

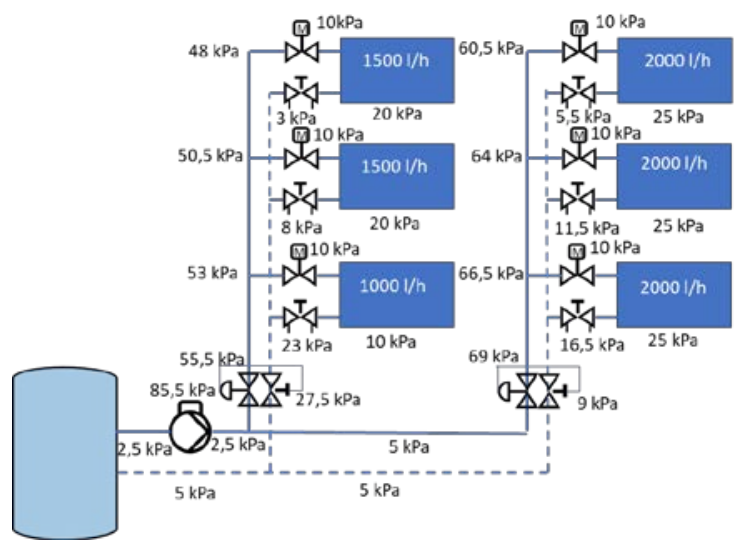

Fig.3 - ON-OFF Control valves, single circulating pump

We can observe, that even in nominal flow conditions, the system will deal with significant pressure drop over the constant differential-pressure controller.

Fig.4 is presenting the same example, but using dedicated pump for each riser, what will automatically eliminate the differential pressure controller need on the risers.

Considering in both cases that pumps are according to European norms with VFD control based on pressure, we can observe in Table 1, the annual cost difference calculated on 150 days of cooling season.

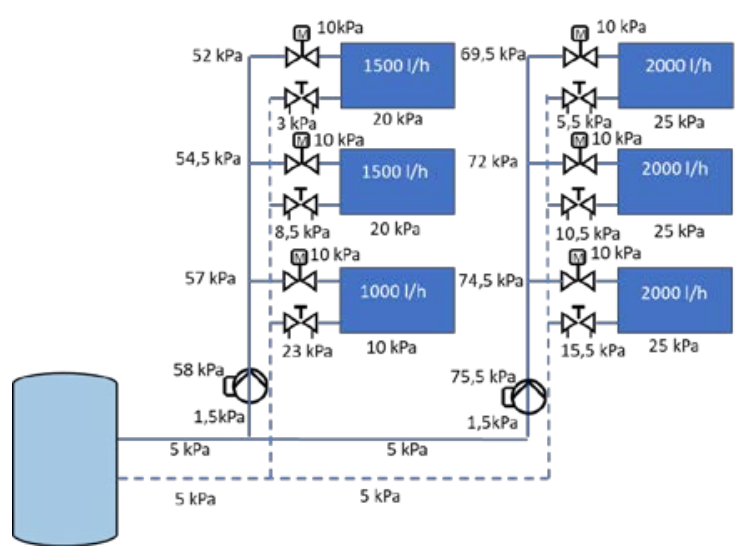

Fig.4 - ON-OFF Control valves, distributed pump scheme
Overall results will show about $15 \%$ lower electric load on the 2 pumps compared to one pump, while annual electric consumption could be lower by $12-38 \%$, depending on pump control type - Constant differential pressure versus proportional differential pressure.

Analysing first branch on Fig. 4 we can see, that $58 \mathrm{kPa}$ total head of the pump is split in $25 \mathrm{kPa}$ of pressure loss on pipes on design flow condition, while the fares unit needs $33 \mathrm{kPa}$ including fully open balancing valve. Avoiding balancing valve at this unit is not recommended, since design stage is always dealing with theoretical pressure losses, consequently designers usually assume some safety margins over the pump head, which could result on overflow condition in lack of balancing.

Table 1 - Solution comparison for Fig. 3 and Fig.4

\begin{tabular}{|l|c|c|c|}
\hline Figure Nr. & Fig.3 & \multicolumn{2}{|c|}{ Fig.4 } \\
\hline Pump nr. & Pump. 1 & Pump. 1 & Pump. 2 \\
\hline Manufact. & \multicolumn{3}{|c|}{ Grundfos } \\
\hline Model & \multicolumn{3}{|c|}{ Magna 3 } \\
\hline Ref. model & $40-120 \mathrm{~F}$ & $25-80$ & $32-120 \mathrm{~F}$ \\
\hline Flow & $10 \mathrm{~m}^{3} / \mathrm{h}$ & $4 \mathrm{~m}^{3} / \mathrm{h}$ & $6 \mathrm{~m}^{3} / \mathrm{h}$ \\
\hline Head & $85.5 \mathrm{kPa}$ & $58 \mathrm{kPa}$ & $75.5 \mathrm{kPa}$ \\
\hline P1 & $398.3 \mathrm{~W}$ & $111.4 \mathrm{~W}$ & $227.1 \mathrm{~W}$ \\
\hline Efficiency & $59.6 \%$ & $57.8 \%$ & $55.4 \%$ \\
\hline Control & Const. $\Delta \mathrm{p}$ & Const. $\Delta \mathrm{p}$ & Const. $\Delta \mathrm{p}$ \\
\hline An. Cons. & $954 \mathrm{kWh}$ & $249 \mathrm{kWh}$ & $594 \mathrm{kWh}$ \\
\hline Control & - & Prop. $\Delta \mathrm{p}$ & Prop. $\Delta \mathrm{p}$ \\
\hline An. Cons. & - & $184 \mathrm{kWh}$ & $416 \mathrm{kWh}$ \\
\hline
\end{tabular}

Cooling systems with overflow often suffer by low $\Delta t$ syndrome, which most of the time result in inefficient work of chiller plant.

When considering sum of pressure losses in pipes as close to half of the total pressure loss, we could consider working with proportional pressure. Depending on pump type and manufacturer, some of the VFD driven pumps allows to change the gradient of the control curve by changing pressure at 0 flow to different value than $\mathrm{H}_{\text {pump }} / 2$.

When we have different units with variable design flow demand grouped on one branch will be difficult to avoid over- or underflow in some certain units. Therefore, it is recommended to group units with similar characteristics on one branch, making life easier (as much as possible).

\subsection{Modulating control valves.}

In case of systems with constant supply temperature on the airside (or constant temperature and variable load in case of technological systems) simple ON-OFF control is no longer enough. Influence might come for example from fresh air parameters (in case of airhandlers) and return air temperature, what will determinate different cooling demand over the coil. In these particular cases the PI controller of the controlling system will open in differentiate way the control valve. Control valves partly open will deal with different pressure drop, therefore, valve authority described in section 1 will get higher 
importance than in our previous case of ON-OFF control.

Fig. 5 presents schematic of an office building riser on five levels, where same type of units with constant supply temperature are used. They all work with modulating valves. As units are same type, but each level might have tenants with different cooling demand things are getting complicated on the balancing side.

This example still use single pump on riser, which is Proportional Pressure controlled. Each level receives a main balancing valve and each unit is balanced. Due to long distribution network and variable conditions pump riser receives a partner valve for balancing the entire riser. Typical for office buildings, that at the beginning not all the floors are occupied, commissioning and installation of units is done according to the need.

Even if the pump is speed controlled, a balancing valve might be needed to limit the maximum flow over the riser, unless the pump maximum curve can be limited, or the pump has got electronic flow limitation [5],[6],[7]

When pumps with their built-in electronics are able to limit the flow at maximum value, the partner valve could be left, which results in lower total pressure drop. Attention must be carried out during the balancing of the system, since compensate method balancing as basis needs the reference valve (partner valve) [8.]

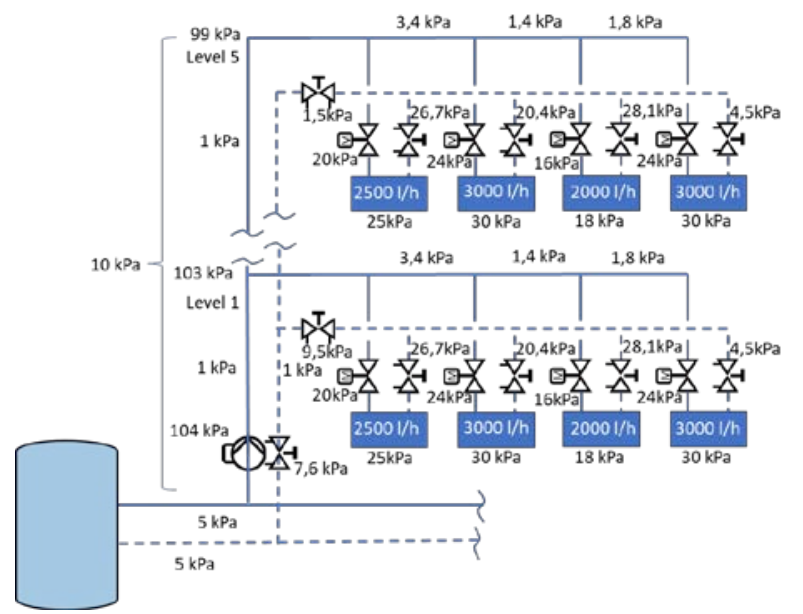

Fig.5 - Modulating valve -5 floor office building riser

Fig. 5 presents the schematic with the lowest and highest level. The other levels are dealing with same layout, flows from airhandler to another varies with ratio of maximum 0.66 to 1 .

When considering valve authority, as $\beta$ 'min (5), we have to check the pump head. If pump head is with constant differential pressure control of VFD, it means that even at low flow condition, the pressure stays the same. If this pressure is measured across the pump (as standard) and we assume that only one unit is working with $20001 / \mathrm{h}$ and $104 \mathrm{kPa}$ pressure we could see that our minimum valve authority will be below controllable range since $16 \mathrm{kPa} / 104 \mathrm{kPa}$ will result 0.153 . With such a high pressure difference, we will assist at valve noise. Meanwhile, as the other units are closed, pressure drop in pipe will be very low, consequently the entire pressure go across the control valve, coil and the balancing valve. With all these together, the control valve will suffer the most, as it will be in overflow. One possible solution is to install a DP controller valve before coil, but this will result just in waste of energy at level for sake of protecting the valve and reducing the noise.

A second alternative, lower as investment cost and much more energy efficient is to create a proportional pressure, which will offer a better minimum authority level. In case of $104 \mathrm{kPa}$ pressure at design flow with the standard proportional pressure 0 flow will result $52 \mathrm{kPa}$ pressure. At $20001 / \mathrm{h}$ flow this will result around $55 \mathrm{kPa}$ differential pressure produced by the pump.

Calculating with this control mode, $\beta{ }_{\text {min }}$ will be $16 \mathrm{kPa} / 55 \mathrm{kPa}=0.29$, resulting in better controllability.

As even better controllability in case of modulating control valves it could be better to put the valves on return, so in low flow conditions, pressures will be reduced first on the heat exchanger and balancing valve, $\beta_{\min }$ will result in higher value.

Taking as reference a pump model suitable to work with proportional differential pressure and delivering the scenario flow and pressure $(52.5 \mathrm{~m} 3 / \mathrm{h}$ and $104 \mathrm{kPa})$ a Grundfos pump, type TPE3 $80-180$ s will be able to modulate down to $20001 / \mathrm{h}$ at $55 \mathrm{kPa}$, but efficiency of the pump will be $12 \%$ only - see Fig. 6

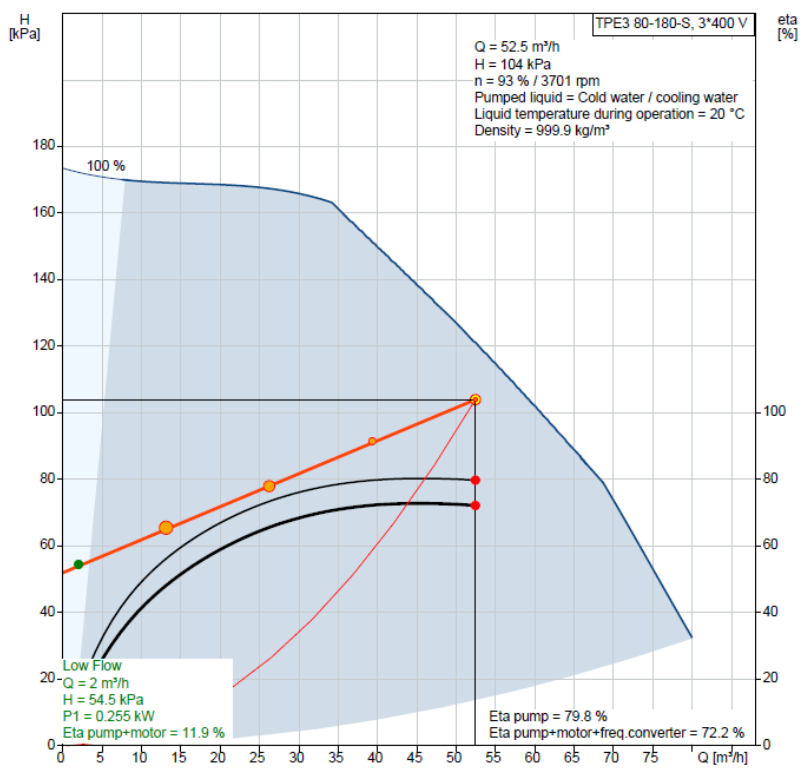

Fig.6 - Circulating pump model for Fig.5

In this proper case, even at very low load, which is unprobably to happen in normal conditions (single unit working on all the riser), the efficiency will be very low. However, a more probably situation would be several units, where each will be opened partly. In this case using proportional pressure, still a better controlability is obtained.

Analysing the improvement possibilities, one of the simpliest solution would be using one pump for each level. When evaluating the riser, we can see that on common loop we have one balancing valve, while on the 
level branches we have one more zone balancing valve. If we sum up this, will result in total pressure drop of 9.1 $-17 \mathrm{kPa}$ pressure drop, which is less than $20 \%$ of the entire loop.

Making a trial to optimise this riser, we will observe, that flow of each floor is about $10.5 \mathrm{~m}^{3} / \mathrm{h}$, pressure drop is up to $94.9 \mathrm{kPa}$, which by range of pumps will result in smaller pumps, mainly wet runners. The original proposed pump is a TPE3 unit from Grundfos, which is a high efficiency singlestage pump. Looking on Fig.6 we can see that total efficiency of pump and motor is about $72 \%$.

If we are looking between pump manufacturers, latest technology glandless pumps (wet runners) are runinng with higher efficiencies than old models, but still far from glanded pumps efficiency in most of the cases.

Typically, glandless wet runners do have efficiencies up to $60 \%$.

If we are looking over the fact, that in case of Fig. 5 we can reduce only about $10 \%$ in pressure demand, but meanwhile the pump efficiency will be lower by about $15-20 \%$ we can summarise an possible easier controlability, by having a significantly higher electrical consumption.

Table2 -Fig.5 - 1 main pump parameters

\begin{tabular}{|l|c|l|c|c|c|}
\hline Pump & Flow & Head & P1 & Eff. & Cons. \\
\hline TPE3 & {$[\mathrm{m} 3 / \mathrm{h}]$} & {$[\mathrm{kPa}]$} & {$[\mathrm{W}]$} & {$[\%]$} & $\mathrm{kWh}$ \\
\hline \hline 80-180S & 52.5 & 104 & 2098 & 72.2 & 3064 \\
\hline \multicolumn{2}{|l|}{ Total El. Load } & $\mathbf{2 0 9 8}$ & & \\
\hline \multicolumn{2}{|l|}{ Average Efficiency } & & $\mathbf{7 2 . 2}$ & \\
\hline \multicolumn{2}{|l|}{ Annual electric consumption } & & & $\mathbf{3 0 6 4}$ \\
\hline
\end{tabular}

Table3 -Fig.5 - Each Floor with own pump

\begin{tabular}{|c|c|c|c|c|c|}
\hline Pump & Flow & Head & P1 & Eff. & Cons. \\
\hline Magna3 & {$[\mathrm{m} 3 / \mathrm{h}]$} & {$[\mathrm{kPa}]$} & [W] & {$[\%]$} & $\mathrm{kWh}$ \\
\hline $40-150 \mathrm{~F}$ & \multirow{5}{*}{10.5} & 95 & 462 & 59.6 & 779 \\
\hline $40-150 \mathrm{~F}$ & & 93 & 452 & 59.8 & 759 \\
\hline $40-150 \mathrm{~F}$ & & 91 & 441 & 59.9 & 740 \\
\hline $40-120 \mathrm{~F}$ & & 89 & 425 & 60 & 719 \\
\hline $40-120 \mathrm{~F}$ & & 87 & 419 & 60.3 & 701 \\
\hline \multicolumn{3}{|c|}{ Total El. Load } & 2199 & & \\
\hline \multicolumn{3}{|c|}{ Average Efficiency } & & 59.92 & \\
\hline \multicolumn{3}{|c|}{ Annual electric consumption } & & & 3698 \\
\hline Q Total & 52.5 & & & & \\
\hline \multicolumn{2}{|c|}{ H Average } & 91 & & & \\
\hline
\end{tabular}

Table 2 and Table 3 shows the 2 scenarios simulation for the pump consumptions and data. We can see, that pump efficiency for glanded pump is $20 \%$ higher than glandless pumps average. When we are comparing the savings in pressure losses between the 2 solutions, this is only $12.5 \%$, which means that overall we can not save more energy by swithcing to distributed pumping solution here.

In case of example presented at 2.1 - with ON-OFF control valves, both scenarios (Fig.3 and Fig.4) were same category of pump, Magna3 type glandless wet runners. This means, that their range of efficiency is similar, differences are small. Meanwhile, Fig.3 was using a $\Delta$ p control for each branch, while Fig.4 was using proportional control mode. These 2 control modes are significantly different by means of consumption and electric load on lower flow conditions, while efficiency rate is not decreasing so much at similar flow conditions. We conclude, that eficientization on overall runinng costs as well as investments we could earn by splitting pumping duties only if the ratio of pressure drop reduction is greater than efficiency decrease (if any) of pump because of using smaller pumps.

\subsection{Cooling systems with large cooling capacity units.}

Previous sections (2.1 and 2.2) were presenting alternatives, where relatively small units been installed on branches. We have seen advantages of splitting pumping demand and using more efficient control methods, as well as risers, where real energy saving can't be easily achieved. The last example is showing a connection of Primary-Secondary chilled water distribution versus Primary - Distributed system.

We have seen that simillar efficiency range pumps can be used to reduce pumping costs if we can eliminate complicated balancing valves. On some risers or branches heavy pressure losses are taken by balancing valves, so we still try to limit through numer of the pumps.

When we are trying to realize a Distributed pumping schematic [9.] we plan to use instead one central pumping station several smaller pumps. This means, that all smaller pumps must push water through common piping, as well as in some cases different units might start in different times, which could result in hunting the water (one pump might cut down the water from other). To avoid hunting, the best practice is to size the main pipe as large as possible. This will reduce the pressure drop and speed in this part.

Primary flow of the chilled water is depending on chiller control and construction features. Still most of running chiller plants has got chillers in constant flow across the evaporator, while more and more units are installed in Variable Primary Flow version. [10.]

When several chillers are connected in parallel, in classic connection each chiller is equipped with its own pump.

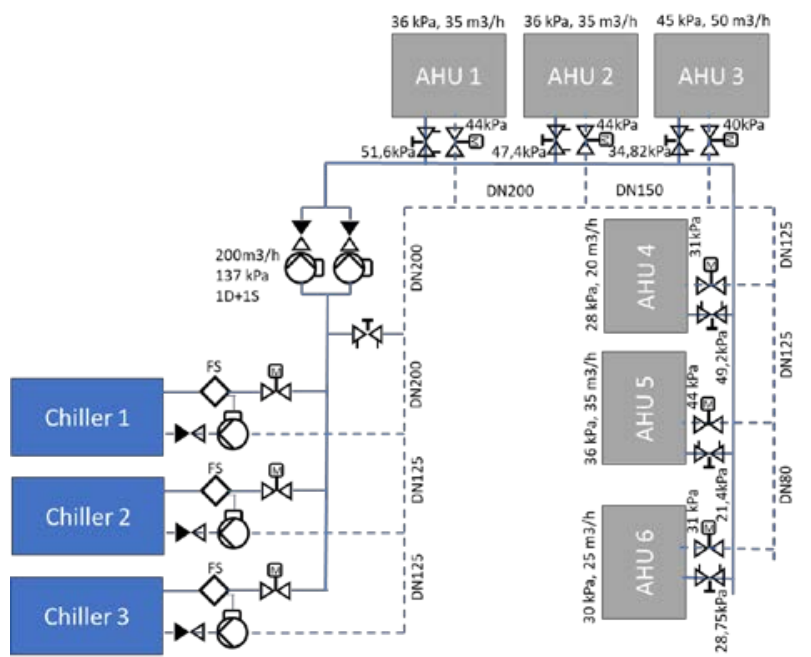

Fig.7 - Primary-Secondary Chilled water distribution 
Fig.7 presents primary loop with cascade installed chillers with direct return connection. Particularity of solution is the use of Flow Sensor (FS) to control pumps. Using a Variable Speed Drive Pump will result in matching right flow. [12.]

In case of Constant Primary Flow application, the pump speed is adjusted to run at apropiate speed to generate the preset flow over the system. When sizing the primary loop, we have to deal with collecting loop, where all cascade chillers are sharing same pipe. This means that equal sized chillers will contribute in our example by $33 \%$ of total flow each. If our cooling demand is only $25 \%$ means that only one chiller will run.

Suposing, that our main distribution pipe primary loop is made of pipe section according to Fig. 8 - the pressure drop across main pipe will be modified by $13 \mathrm{kPa}$ only due to flow quantity $(67 \mathrm{~m} 3 / \mathrm{h}$ vs $200 \mathrm{~m} 3 / \mathrm{h})$, which will be suplimented in normal conditions by the pressure drop of the balancing valve needed in case of simple pressure control or in case of the constant speed pumps. The pressure drop of a STAF125 valve for the $670001 / \mathrm{h}$ is equal to $5 \mathrm{kPA}$, which total means $18 \mathrm{kPa}$. This pressure change will result in about $0.5 \mathrm{~kW}$ savings in electric load. As partload condition is the most common in a cooling system, this means a heavy number of hours, where this savings can be summed up.

In meantime, keeping the flow constant will result in prevention of the overflow across the evaporator. If Evaporator is in overflow, means that chiller efficiency could decrease in some certain cases - it depends on how high the flow is compared to maximum amount of water designed to cross the evaporator.

On secondary loop Fig. 8 is giving the diference, where in comparison with Fig.7 it has got distributed flow, different pipe diameter in secondary loop.

We can see that in all cases flows are considerably high on each AHU unit. Nevertheless some of the units are in big difference of flow, minimum flow is $20 \mathrm{~m} 3 / \mathrm{h}$, while largest is $50 \mathrm{~m} 3 / \mathrm{h}$. [13.]

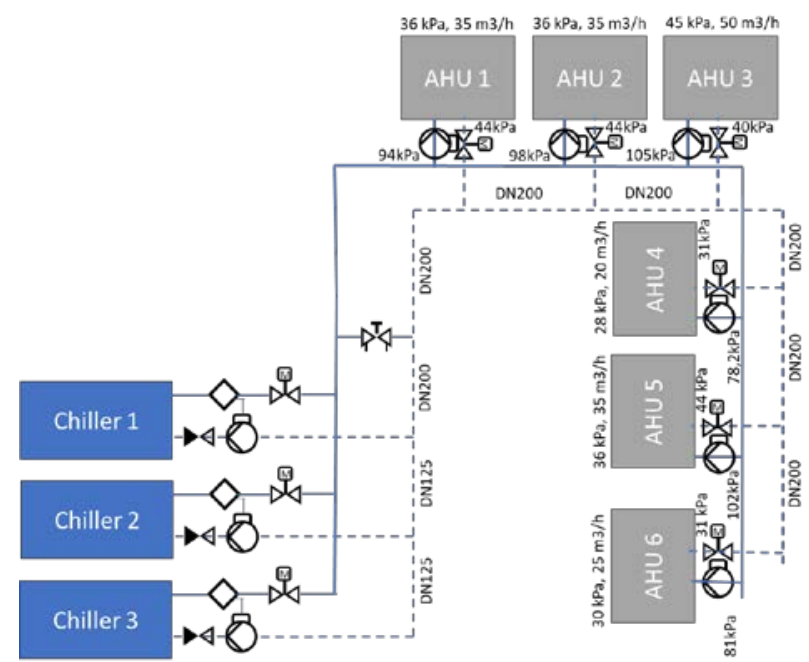

Fig.8 - Primary- Distributed loop
Calculated difference in pressure drop between the two secondary loops is $34.5 \mathrm{kPa}$ on design flow condition, while we can see that on each AHU unit we have got the balancing valve left in case of Distributed loop.

The reason is simple, in case of the second solution, electronic pumps are able to limit their maximum flow supplied, which will overtake the role of the balancing valve. This results in additional decrease of overall pressure drop.

In general 60 to $80 \mathrm{kPa}$ is saved by changing the solution.

Meanwhile, when the control valves are placed on return of the AHU units, and pumps are installed with proportional pressure, we could see that valves minimum authority will be fairly good, as pump head will decrease to half of the nominal head in 0 flow condition, and pressure drop of fully open control valve is close to the pressure drop of the coil, so their authority is around 0.5 . Control of flow will be fairly precise by modulating the valve.

Table 4 shows the results of the pump calculation for Fig. 7 case of secondary loop. Calculation is identical of previous simulations, where 150 days are calculated and pressure control is PP pressure control.

Table.4 - Fig.7 pump details.

\begin{tabular}{|c|c|l|c|l|l|}
\hline Pump & Flow & Head & P1 & Eff. & Cons. \\
\hline TP+VFD & {$[\mathrm{m} 3 / \mathrm{h}]$} & {$[\mathrm{kPa}]$} & {$[\mathrm{kW}]$} & {$[\%]$} & $\mathrm{kWh}$ \\
\hline \hline 150-155/4 & 200 & 137 & 10.94 & 72.50 & 17324 \\
\hline \multicolumn{2}{|l|}{ Total El. Load } & $\mathbf{1 0 . 9 4}$ & & \\
\hline \multicolumn{2}{|l|}{ Average Efficiency } & & $\mathbf{7 2 . 5 0}$ & \\
\hline \multicolumn{2}{|l|}{ Annual electric consumption } & & & $\mathbf{1 7 3 2 4}$ \\
\hline
\end{tabular}

Table.5 - Fig. 8 pump details.

\begin{tabular}{|c|c|c|c|c|c|}
\hline Pump & Flow & Head & P1 & Eff. & Cons. \\
\hline TPE3 & {$[\mathrm{m} 3 / \mathrm{h}]$} & {$[\mathrm{kPa}]$} & {$[\mathrm{KW}]$} & {$[\%]$} & $\mathrm{kWh}$ \\
\hline $50-200 \mathrm{~S}$ & 35 & 94 & 1.51 & 64.1 & 2050 \\
\hline $50-200 \mathrm{~S}$ & 35 & 98 & 1.51 & 64.1 & 2050 \\
\hline $80-180 \mathrm{~S}$ & 50 & 106 & 2.005 & 72.6 & 2994 \\
\hline $40-180 \mathrm{~S}$ & 20 & 78 & 0.71 & 61 & 997 \\
\hline $50-200 \mathrm{~S}$ & 35 & 102 & 1.514 & 64.1 & 2050 \\
\hline $50-150 \mathrm{~S}$ & 25 & 82 & 0.838 & 66.9 & 1272 \\
\hline \multicolumn{3}{|c|}{ Total El. Load } & 8094 & & \\
\hline \multicolumn{3}{|c|}{ Average Efficiency } & & 65.96 & \\
\hline \multicolumn{3}{|c|}{ Annual electric consumption } & & & 11413 \\
\hline Q Total & 200 & & & & \\
\hline \multicolumn{2}{|c|}{ H Average } & 93.3 & & & \\
\hline
\end{tabular}

In the given comparison we can see that even if most of the cases are pointing to a smaller pump efficiency, overall due to the elimination of excessive pipe friction loss and balancing valve installation to be avoided we can realise a pumping system individual to each AHU unit.

Overall savings are about $34 \%$ on distributed schematic, while price of the 2 solutions are similar as value.

\section{Conclusions}

Optimisation of hydraulic loop does have focus on dynamic data of flow, which has influence on entire 
system. We often influence the flow criteria by changing $\Delta t$ of system or subsystems. However, flow cirteria is influencing the entire hydraulic system and also the Lyfe Cycle Cost ratio. Optimising the valves and pumps number in a cooling distribution loop is important and essential. On traditional distribution system designing phase is quicker, because it is always sized on total flow of units and worst case unit pressure demand.

When we are doing distributed pumping solution we will need to size more pump and also the each loop/subloop must be carefully selected.

Overall it means more work on designing and conceptual stage.

As seen in our practical examples, if small size units are equipped is better to get more units together, consequently balancing valves are needed.

When hydraulic power need is defined as long as they are bellow $2 \mathrm{~kW}$ load, pumps shall be selected as much as possible glandless pumps, except situations where presure demand is indicated larger pump needs.

If each unit could receive a pump (case of large units like airhandlers, design flows over 5000-80001/h), balancing valves could be easily avoided. If these are taken out, pressure drops over the system could be lower significantly. More pumps does not necesarly means larger investment costs - at large pump lot of balancing valves are required. They may endup with value of the pump differences.

Due to constructional issues of pumps and available techologies, the smaller wet runners will always operate at lower efficiency - case valid for some glanded inline pumps - while larger pumps could get way much better efficiencies $-70-80 \%$.

Important aspect of distributed pumping solutions is that balancing is easier for the entire loop.

System safety is better. If one pump fails, others can continue serving their area, so only small part of the building loop will be malfunctioning.

On other hand, more pumps with more moving parts will demand higher service cost, as each pump in particulare needs to receive its adequate service over the time.

However, when we are calculating the Life Cycle Cost of a system, most of the cost is built up by regular use electric consumption, while service and net unit price takes about $15 \%$ together.

Whichever the solution is, common sense and proper zoning is needed. In Western European region more zoning is used on systems, while Eastern European countries in many cases are using larger pumping lots for big areas.

As rule of tumb a loop should be designed in a way that preferably no more than 2 balancing valves to be connected in series, as their pressure losses will be summed up an end on pump electric use.
Each $1 \mathrm{~m}$ of savings in head on pumps at a flow of $10 \mathrm{~m} 3 / \mathrm{h}$ will result in a reduction of over $40 \mathrm{~W}$ electric load.

By reducing pressure drop will result in smaller pump, which could have smaller pressure available, so authority of control valve will be better to control. Consequently the better authority will lead to higher comfort level,. If flows are high in the heat exchanger, low $\Delta t$ syndrome could occure in our system, while occupants comfort level could be out of optimum. In this case problems are doubled, as discomfort of occupants is not good and high runinng costs are neither good for building operators and owners. Practical test will be conducted in close future as part of some Pump/Energy Audit processes

\section{References}

1. R. Petitjean, Total Hydronic Balancing, 148-154, 2012

2. O.J.E.C, COMMISSION REGULATION (EC) No 641/2009, L191/39, 2009

3. Belimo, Pressure Independent Characterized Control Valves, (2007)

4. Grundfos, Pump Handbook, 97530403, 107

5. Grundfos, Magna3 Data Booklet- model D, 99218286, 23

6. Grundfos, TP(E)(3)(D) Databooklet, V7124417, 69

7. Armstrong, Design Envelope 4300 \& 4380, 101.80iec, 28

8. R. Petitjean, Total Hydronic Balancing, 313, 2012

9. Grundfos, Optimizing Chilled Water Distribution Without Valves,

10. Daikin, Chiller Application Guide, AG 31-003-4

11. Trane, Chiller System Design and Control

12. R. Petitjean, Total Hydronic Balancing, 313, 2012

13. IMI International, Dividing a hydronic system in modules, https://www.imihydronic.com/sites/EN/en-us/knowledgecentre/HydronicTheory/Pages/default.aspx

14. A.Retezan, T.E.Man, L.C.Ocolisan, G.Vitan, I.P.C.C.A, Eficientizarea Pompării Industriale cu Ajutorul Curbelor de Funcționale Caracteristice ale Echipamentelor - Partea I, 24, 98, (2015)

15. A.Retezan, T.E.Man, L.C.Ocolisan, G.Vitan, I.P.C.C.A, Eficientizarea Pompării Industriale cu Ajutorul Curbelor de Functionale Caracteristice ale Echipamentelor - Partea II, 24, 105, (2015)

16. Sz.Z.Geyer Ehrenberg, B.I.T, Pompele de Circulație Electronice și Efectele Lor în Instalațiile de Incălzire, Partea I, 6, 28, (2016)

17. Sz.Z.Geyer Ehrenberg, B.I.T, Pompele de Circulație Electronice și Efectele Lor in Instalațiile de Incălzire, Partea II, 7, 62, (2016)

18. ARTECNO, V.I.S.E, Înc. Man. De Inst, II, 103-120, (2010) 